\title{
Cross-Reactivity against Naja sumatrana (Black Spitting Cobra) Envenoming from the Haffkine Antivenom in a Mouse Model
}

\author{
Gregory Cham, ${ }^{1}$ Francis Lim, ${ }^{2}$ Arul Earnest, ${ }^{3}$ and Ponnampalam Gopalakrishnakone ${ }^{4}$ \\ ${ }^{1}$ Emergency Medicine Department, Alexandra Hospital, 378 Alexandra Road, Singapore 159964 \\ ${ }^{2}$ Singapore Zoological Gardens, 80 Mandai Lake Road, Singapore 729826 \\ ${ }^{3}$ Centre for Quantitative Medicine, Duke-NUS Graduate Medical School, 8 College Road, Singapore 169857 \\ ${ }^{4}$ Venom and Toxin Research Programme, Department of Anatomy, Yong Loo Lin School of Medicine, National University of Singapore, \\ 4 Medical Drive, Block MD10, Singapore 117597
}

Correspondence should be addressed to Gregory Cham; gchamwm@gmail.com

Received 8 June 2013; Accepted 11 July 2013

Academic Editors: F. Ducancel, B. K. Mandal, and A. Pessina

Copyright (C) 2013 Gregory Cham et al. This is an open access article distributed under the Creative Commons Attribution License, which permits unrestricted use, distribution, and reproduction in any medium, provided the original work is properly cited.

\begin{abstract}
Naja sumatrana is the dominant cobra species in Malaysia, Singapore, Borneo, and Sumatra, and it does not have specific antivenom. The Haffkine antivenom has been advocated instead. This study aims to determine the efficacy of this antivenom against Naja sumatrana envenoming using a mouse model. Methods. Male Swiss albino mice were used. Intravenous $\mathrm{LD}_{50}$ was first determined separately for Naja naja and Naja sumatrana venom. $\mathrm{ED}_{50}$ was determined by preincubating antivenom with each venom at 2.5 $\mathrm{LD}_{50}$ before administering the mixture into the tail vein. Validation was carried out using a challenge test. Each mouse received $111 \mu \mathrm{g}$ of Naja sumatrana venom intramuscularly followed by intraperitoneal administration of dilute Haffkine antivenom. Survival was recorded 24 hours after envenoming. Results. The $\mathrm{LD}_{50}$ of Naja naja venom was $78.13 \mu \mathrm{g}$, standard error $(\mathrm{SE}) 13.3 \mu \mathrm{g}$. The $\mathrm{ED}_{50}$ of the Haffkine antivenom against Naja naja venom was $45.9 \mathrm{mg}$, SE $7.5 \mathrm{mg}$. The $\mathrm{LD}_{50}$ and $\mathrm{ED}_{50}$ of Naja sumatrana venom were $55.5 \mu \mathrm{g}$, SE $12.0 \mu \mathrm{g}$; and $73.9 \mathrm{mg}$, SE $12.0 \mathrm{mg}$, respectively. The intra-peritoneal $\mathrm{ED}_{50}$ against $111 \mu \mathrm{g}$ intramuscular Naja sumatrana venom was $136.95 \mathrm{mg}$, SE $36.74 \mathrm{mg}$. Conclusion. The Haffkine polyvalent antivenom exhibited cross-neutralisation against Naja sumatrana venom when used at a higher dose.
\end{abstract}

\section{Introduction}

1.1. Background and Importance. Naja sumatrana, commonly known as the black spitting cobra or Equatorial spitting cobra, is the dominant cobra species in Peninsular Malaysia, Singapore, Borneo, and Sumatra [1]. It was estimated that the highest burden of snake bites exists in South Asia, Southeast Asia, and sub-Saharan Africa [2]. Cobra bites are common in Peninsular Malaysia and require significant medical intervention $[3,4]$. However, snake bites are considered uncommon in largely urban Singapore $[5,6]$.

Unfortunately specific antivenom therapy against the Naja sumatrana does not exist. The Haffkine antivenom was arbitrarily advocated as an antivenom. It is an equine polyvalent antivenom raised against the Indian binocellate cobra
(Naja naja), common krait (Bungarus caeruleus), Russell's viper (Vipera russelli), and saw-scaled viper (Echis carinatus) [7]. However, these species of snakes are not normally found in Southeast Asia. The antivenom composition of the Haffkine was chosen for the treatment of black spitting cobra snake bites due to the empirical belief that cobras are originated from the Naja naja. These species are, however, considered to be separate now. It is unknown if the Haffkine product has any effective paraspecific activity against the Naja sumatrana venom. There have been no previous papers that report the outcomes of patients given this antivenom for black spitting cobra bites.

This study aims to examine if effective cross-neutralisation exists for Naja sumatrana envenoming when using the Haffkine antivenom. 


\section{Materials and Methods}

2.1. Study Design. Using comparable doses of Naja naja or Naja sumatrana venom, this study analysed the neutralising capability of the Haffkine antivenom in a mouse model. This was followed by a challenge test by giving a fixed dose of Naja sumatrana venom intramuscularly and subsequent attempt at rescue with the antivenom.

2.2. Materials. Naja naja venom was purchased from Accurate Chemical Corporation (New York, USA). Naja sumatrana venom was pooled from five local adult Naja sumatrana cobras housed at the zoo, lyophilised, and stored at $-20^{\circ} \mathrm{C}$. The antivenom used was a commercial product from the Haffkine Bio-Pharmaceutical Corporation (Mumbai, India).

2.3. Setting and Animal Subjects. Ethics committee approvals from Tan Tock Seng Hospital (TTSH) and Singapore zoo were first sought. The experiments were carried out in the Animal Research Laboratory at TTSH. Only male Swiss albino mice about five weeks of age were used. The mice were bred locally at the Laboratory Animals Centre and weighed between 25.5 and 37.5 grams.

2.4. Study Protocol. The animals were quarantined for 24 hours prior to conducting the experiments. Food and water were available ad libitum throughout the study.

2.4.1. Determining the Lethal Dose $\left(L D_{50}\right)$. The $\mathrm{LD}_{50}$ is the dose of venom required to kill $50 \%$ of mice within 24 hours. Each venom was reconstituted by dissolving lyophilised venom in normal saline. Further concentrations were obtained from serial dilutions using additional saline. The lethal toxicity was determined by injecting $0.2 \mathrm{~mL}$ of venom, at various concentrations per mouse, into the tail vein [8]. The injections were performed using a $1 \mathrm{~mL}$ syringe fitted with a 29 -gauge needle. The venom was warmed to $37^{\circ} \mathrm{C}$ for 30 minutes before injection. Six mice were used for each dilution. The mice were observed for 24 hours.

2.4.2. Determining the Effective Dose $\left(E D_{50}\right)$. The $\mathrm{ED}_{50}$ is the dose of antivenom required to produce $50 \%$ survival of mice within 24 hours when used against intravenous venom at $2.5 \mathrm{LD}_{50}$ for each mouse. The venom and antivenom were incubated prior to intravenous administration. Lyophilised venoms of Naja naja and Naja sumatrana were obtained from the same batch used for $\mathrm{LD}_{50}$ determination. The Hafflkine antivenom used to neutralise both types of cobra venom was reconstituted from the same batch. Twofold serial dilution using normal saline was made to obtain additional concentrations of antivenom. Venom at $2.5 \mathrm{LD}_{50}$ and antivenom of various concentrations were mixed and incubated at $37^{\circ} \mathrm{C}$ for 30 minutes prior to injection. Each mouse was injected with $0.2 \mathrm{~mL}$ of venom-antivenom mixture into the tail vein. Four mice were used for each of the dilution groups. The mice were observed for 24 hours.

2.4.3. Haffkine Antivenom versus Naja sumatrana Venom Challenge Test. Four groups of four male Swiss albino mice
TABLE 1: Weights of the mice compared between groups.

\begin{tabular}{lcccc}
\hline & $n$ & $\begin{array}{c}\text { Mean } \\
\text { weight } \\
\text { (grams) }\end{array}$ & $\begin{array}{c}\text { Std. } \\
\text { deviation }\end{array}$ & Range \\
\hline $\begin{array}{l}\text { Group for Naja naja } \text { LD }_{50} \\
\text { determination }\end{array}$ & 24 & 29.98 & 0.99 & $27.5-32.0$ \\
$\begin{array}{l}\text { Group for Naja sumatrana } \\
\text { LD }\end{array}$ determination & 24 & 29.42 & 2.41 & $25.5-37.5$ \\
$\begin{array}{l}\text { Group for Naja naja } \mathrm{ED}_{50} \\
\text { determination }\end{array}$ & 12 & 28.50 & 0.95 & $27.0-30.5$ \\
$\begin{array}{l}\text { Group for Naja sumatrana } \\
\text { ED }\end{array}$ & 12 & 30.46 & 1.14 & $28.0-32.0$ \\
\hline Total determination & 72 & 29.62 & 1.72 & $25.5-37.5$ \\
\hline
\end{tabular}

were used. Each was given an intramuscular injection of arbitrarily two times the intravenous $\mathrm{LD}_{50}$ into the left thigh muscle from the same batch of reconstituted lyophilised Naja sumatrana venom, in $0.05 \mathrm{~mL}$. After two minutes, this was followed by an intraperitoneal administration of Haffkine antivenom at various concentrations, in two $\mathrm{mL}$.

2.5. Measurements. The end point for all the above experiments was death of the experimental animal. Total number of deaths was recorded 24 hours after envenoming.

2.6. Data Analysis. The $\mathrm{LD}_{50}$ and $\mathrm{ED}_{50}$ were calculated using the Reed-Muench method [9]. The standard error was calculated according to the method by Pizzi [10]. One-way ANOVA was used to compare the mean weight of the mice for the four groups. Weight was assumed to be normally distributed in the different groups. The Bonferroni method of comparison was used to adjust for the multiple comparisons. Level of significance was set at 5\%, and data analysis was carried out using SPSS (Illinois, USA).

\section{Results}

In most of the groups compared the mice were similar in weight. The mean difference in weight for the overall groups of mice was significant ( $P=0.022$, by one-way ANOVA). Pairwise comparisons using the Bonferroni method showed significant difference between the weight of mice used for Naja naja $\mathrm{ED}_{50}$ and that of Naja sumatrana $\mathrm{ED}_{50}$ determination $(P=0.028)$. However, the actual difference in the means was only $1.96 \mathrm{~g}$. Table 1 summarises the weight of the mice used.

The cohort of mice used in the in vivo challenge test was also significantly smaller than those used in the preincubation experiments.

After tail-vein injection of venom, both groups envenomed with Naja sumatrana and Naja naja venom exhibited weakness and diminished physical activity prior to death.

3.1. $L D_{50}$ of Cobra Venom. Survival times diminished with increasing venom doses. Table 2 summarises the survival of 
TABLE 2: 24-hour-survival of mice after tail-vein envenoming with Naja naja venom.

\begin{tabular}{lccc}
\hline Venom $(\mu \mathrm{g})$ & Lived & Died & Mortality \% \\
\hline 19.5 & 6 & 0 & 0.00 \\
39.1 & 6 & 0 & 0.00 \\
78.1 & 3 & 3 & 50.00 \\
156.3 & 0 & 6 & 100.00 \\
\hline
\end{tabular}

TABLE 3: 24-hour-survival of mice after tail-vein envenoming with Naja sumatrana venom.

\begin{tabular}{lccc}
\hline Venom $(\mu \mathrm{g})$ & Lived & Died & Mortality \% \\
\hline 19.5 & 6 & 0 & 0.00 \\
39.1 & 4 & 2 & 28.57 \\
78.1 & 1 & 5 & 87.50 \\
156.25 & 0 & 6 & 100.00 \\
\hline
\end{tabular}

the mice at 24 hours at various Naja naja venom concentrations, and Table 3 for the Naja sumatrana venom. The $\mathrm{LD}_{50}$ of Naja naja venom was $78.13 \mu \mathrm{g}$, standard error (SE) $13.3 \mu \mathrm{g}$. The $\mathrm{LD}_{50}$ of Naja sumatrana venom was $55.5 \mu \mathrm{g}$, SE $12.0 \mu \mathrm{g}$.

\section{2. $E D_{50}$ of the Haffkine Antivenom against Cobra Venom.} Results of the preincubation experiments are summarised in Tables 4 and 5, for Naja naja and Naja sumatrana, respectively. The data showed a similar dose-response relationship, with improved survival on higher doses of antivenom, with the venom load fixed at $2.5 \mathrm{LD}_{50}$. The $\mathrm{ED}_{50}$ of the Haffkine antivenom against Naja naja venom was $45.9 \mathrm{mg}$, SE $7.5 \mathrm{mg}$. The $\mathrm{ED}_{50}$ of the Haffkine antivenom against Naja sumatrana venom was $73.9 \mathrm{mg}$, SE $12.0 \mathrm{mg}$.

3.3. The $E D_{50}$ of Intraperitoneal Haffkine Antivenom versus Intramuscular Naja sumatrana Venom. After the initial intramuscular envenoming, the mice exhibited paralysis in the left leg but continued to be mobile. The paralysis was recovered gradually particularly among the survivors. Table 6 summarises the survival of the mice at different concentrations of antivenom. The intraperitoneal $\mathrm{ED}_{50}$ against $111 \mu \mathrm{g}$ intramuscular Naja sumatrana envenoming was $136.95 \mathrm{mg}$, SE $36.74 \mathrm{mg}$.

There was no local tissue destruction over the site of injection 24 hours later among the surviving mice.

\section{Discussion}

There have been no published studies addressing antivenom therapy in Naja sumatrana envenoming, but this species represents the dominant venomous snake in this region. Beyond this region, the species might also be found in zoos or in private collections.

The Haffkine polyvalent antivenom exhibits effective cross-neutralisation against Naja sumatrana venom, revealing a stepwise improvement in survival with increasing antivenom dose. The $\mathrm{ED}_{50}$ was higher than the usual effective dose required for Naja naja neutralisation in preincubation
TABLE 4: 24-hour-survival of mice after tail-vein injection of Haffkine antivenom incubated with $2.5 \mathrm{LD}_{50}$ Naja naja venom.

\begin{tabular}{lccc}
\hline Antivenom dose $(\mathrm{mg})$ & Lived & Died & Mortality \% \\
\hline 65.0 & 4 & 0 & 0.00 \\
32.5 & 0 & 4 & 100.00 \\
16.2 & 0 & 4 & 100.00 \\
\hline
\end{tabular}

TABLE 5: 24-hour-survival of mice after tail-vein injection of Haffkine antivenom incubated with $2.5 \mathrm{LD}_{50}$ Naja sumatrana venom.

\begin{tabular}{lccc}
\hline Antivenom dose (mg) & Lived & Died & Mortality \% \\
\hline 104.6 & 4 & 0 & 0.00 \\
52.3 & 0 & 4 & 100.00 \\
26.1 & 0 & 4 & 100.00 \\
\hline
\end{tabular}

TABLE 6: 24-hour-survival of mice after intra-peritoneal Haffkine antivenom following $111 \mu \mathrm{g}$ intramuscular Naja sumatrana envenoming.

\begin{tabular}{lccc}
\hline Antivenom Dose $(\mathrm{mg})$ & Lived & Died & Mortality \% \\
\hline 192.14 & 3 & 1 & 14.29 \\
147.8 & 2 & 2 & 50.00 \\
103.46 & 1 & 3 & 85.71 \\
59.12 & 0 & 4 & 100.00 \\
\hline
\end{tabular}

experiments. However, it is not clear which fraction or a combination of fractions of the Naja naja, Bungarus caeruleus, Vipera russelli, or Echis carinatus antibodies that drove the results we obtained. An in vivo challenge using intraperitoneal Haffkine antivenom, given following the intramuscular Naja sumatrana envenoming, also showed a stepwise dose response as the dose of antivenom was increased.

The quality of snake venom varies between individual snakes and within the same snake milked on different occasions. To improve the consistency of the venom and minimise stress to the snakes, the Cobras were milked in a single sitting, mixed, and lyophilised. Likewise, the antivenoms used were checked to ensure they belong to the same batch in manufacture.

$\mathrm{LD}_{50}$ experiments sought to standardise the lethal dose for each venom in this particular mouse model. $\mathrm{ED}_{50}$ experiments compared the neutralising capacity of a standard antivenom against a comparable venom load. These parameters were useful in the present cross-neutralisation study, and would also prove useful in future antivenom or intervention studies on the subject.

Preincubation experiments were chosen initially to investigate if the Haffkine antivenom had any efficacy against the Naja sumatrana venom. This was considered better than gel diffusion experiments as apparent reactions in gel diffusion plates occur in vitro and may not be uniformly associated with survival. It was anticipated that there would be immediate bioavailability if antivenom was given intravenously; but if venom was administered intramuscularly or subcutaneously, it would have slower onset, more sustained effect, and could remain lethal after the effects of intravenous antivenom have worn off. Preincubation experiments were chosen as 
this technique would control the differences in venom and antivenom bioavailability that may confound the results. Only male mice were used to avoid intergender difference in survival if any.

To validate the results, an in vivo challenge test was considered necessary to simulate a clinical situation. The intraperitoneal $\mathrm{ED}_{50}$ of the Haffkine antivenom against Naja sumatrana was indeed higher than the $\mathrm{ED}_{50}$ in preincubation studies due to the reduced bioavailability of intraperitoneal antivenom compared to the inherently efficient intravenous availability of antivenom in preincubation studies. In anticipation of this, the higher dosages of antivenom required would not be easily miscible in the small volumes compatible with intravenous tail-vein administration. The intraperitoneal route was chosen, as it allowed for greater volumes for antivenom dilution to occur. An intramuscular route of envenoming more closely resembles what happens clinically. The intramuscular envenoming followed by a single dose of intraperitoneal antivenom exhibited compatible pharmacokinetic properties to allow for the observations made in the in vivo challenge tests.

The $\mathrm{LD}_{50}$ varies according to the route of administration, and the intramuscular $\mathrm{LD}_{50}$ was not determined. In the in vivo challenge test, twice the preincubation Naja sumatrana intravenous $\mathrm{LD}_{50}$ dose $(111 \mu \mathrm{g})$ was arbitrarily used intramuscularly, while we explored the $\mathrm{ED}_{50}$. The choice of this dose did not affect the comparisons which were made between groups of mice that differed only in the intraperitoneal doses of the antivenom.

The mice weights were largely comparable between different cohorts. The $1.96 \mathrm{~g}$ difference in mean weights between the mice used for Naja naja $\mathrm{ED}_{50}$ and Naja sumatrana $\mathrm{ED}_{50}$ determination was not significant in practice. It was more crucial for the mice used for $\mathrm{LD}_{50}$ and its corresponding $\mathrm{ED}_{50}$ for the same venom to be comparable.

The venom of the Naja sumatrana shares similar composition with Naja naja $[11,12]$. Cobras have L-amino acid oxidase, phospholipase A2, protease, phosphodiesterase, $5^{\prime}$ nucleotidase, alkaline phosphomonoesterase, hyaluronidase, and acetylcholinesterase in common. These similarities in the lethal components of the venoms may explain the paraspecific activity of the Haffkine antivenom against Naja sumatrana venom. However, regional differences in venom composition may limit the explanation that could be derived from the similarities in venom composition [13].

\section{Limitations and Future Questions}

This experiment was conducted using mice, and the difference between their metabolism and that of humans is significant, but the results would probably hold true for humans. The findings should be correlated with clinical observations in humans. A higher dose of 1.6 times was determined using pre-incubation experiments, and it would likely not apply in a clinical situation.

The observations were made over 24 hours, focusing on the acute lethal effects of Naja sumatrana venom from neuromuscular paralysis. Beyond 24 hours, the venom could remain lethal from other mechanisms, for example, haematological disorders not studied in this experiment.

The experiment reveals effective paraspecific activity against paralysis, between Haffkine antivenom in Naja sumatrana envenoming, when used at a higher dose in this model. The Haffkine is a viable choice of antivenom available to address Naja sumatrana envenoming until specific antivenom is developed, and treatment could be instituted at more efficient and perhaps safer doses.

\section{Acknowledgments}

The authors would like to thank the staff of the Emergency Department and the Animal Research Laboratory in Tan Tock Seng Hospital. They are also indebted to Ms. Kavitha Gunashekar of the Clinical Research Unit for her help with the paper.

\section{References}

[1] W. Wüster, "Taxonomic changes and toxinology: systematic revisions of the asiatic cobras (Naja naja species complex)," Toxicon, vol. 34, no. 4, pp. 399-406, 1996.

[2] A. Kasturiratne, A. R. Wickremasinghe, N. de Silva et al., "The global burden of snakebite: a literature analysis and modelling based on regional estimates of envenoming and deaths," PLoS Medicine, vol. 5, no. 11, pp. 1591-1604, 2008.

[3] I. Jamaiah, M. Rohela, R. Roshalina, and R. C. Undan, "Prevalence of snake bites in Kangar District Hospital, Perlis, West Malaysia: a retrospective study (January 1999-December 2000)," Southeast Asian Journal of Tropical Medicine and Public Health, vol. 35, no. 4, pp. 962-965, 2004.

[4] I. Jamaiah, M. Rohela, T. K. Ng et al., "Retrospective prevalence of snakebites from Hospital Kuala Lumpur (HKL) (1999-2003)," Southeast Asian Journal of Tropical Medicine and Public Health, vol. 37, no. 1, pp. 200-205, 2006.

[5] R. Ponampalam, H. H. Tan, K. C. Ng, W. Y. Lee, and S. C. Tan, "Demographics of toxic exposures presenting to three public hospital emergency departments in Singapore 20012003," International Journal of Emergency Medicine, vol. 2, no. 1, pp. 25-31, 2009.

[6] H. H. Tan, "Epidemiology of snakebites from a general hospital in Singapore: a 5-year retrospective review (2004-2008)," Annals of the Academy of Medicine Singapore, vol. 39, no. 8, pp. 640-647, 2010.

[7] R. C. Kankonkar, S. S. Rao, N. E. Vad, and M. V. Sant, "Efficacy of Haffkine Institute polyvalent antivenin against Indian snake venoms," The Indian Journal of Medical Research, vol. 60, no. 4, pp. 512-516, 1972.

[8] R. D. G. Theakston and H. A. Reid, "Development of simple standard assay procedures for the characterization of snake venoms," Bulletin of the World Health Organization, vol. 61, no. 6, pp. 949-956, 1983.

[9] L. J. Reed and H. Muench, "A simple method of estimating fifty per cent endpoints," American Journal of Epidemiology, vol. 27, no. 3, pp. 493-497, 1938.

[10] M. Pizzi, "Sampling variation of the fifty percent end-point, determined by the Reed-Muench (Behrens) method," Human Biology, vol. 22, no. 3, pp. 151-190, 1950.

[11] M. K. K. Yap, N. H. Tan, and S. Y. Fung, "Biochemical and toxinological characterization of Naja sumatrana (Equatorial 
spitting cobra) venom," Journal of Venomous Animals and Toxins Including Tropical Diseases, vol. 17, no. 4, pp. 451-459, 2011.

[12] N.-H. Tan and C.-S. Tan, "A comparative study of cobra (Naja) venom enzymes," Comparative Biochemistry and Physiology Part B, vol. 90, no. 4, pp. 745-750, 1988.

[13] R. Shashidharamurthy, D. K. Jagadeesha, K. S. Girish, and K. Kemparaju, "Variations in biochemical and pharmacological properties of Indian cobra (Naja naja naja) venom due to geographical distribution," Molecular and Cellular Biochemistry, vol. 229, no. 1-2, pp. 93-101, 2002. 

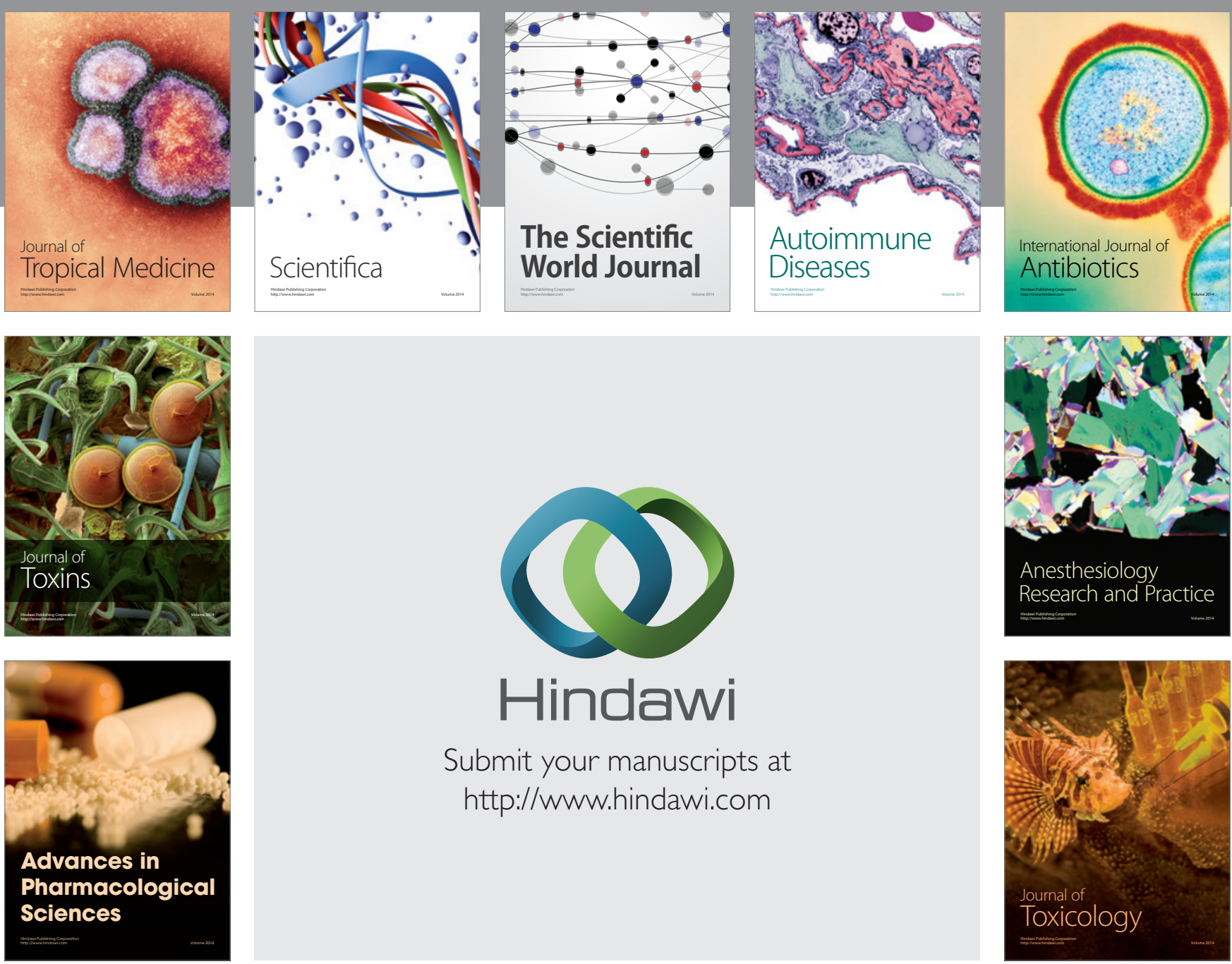

\section{Hindawi}

Submit your manuscripts at

http://www.hindawi.com
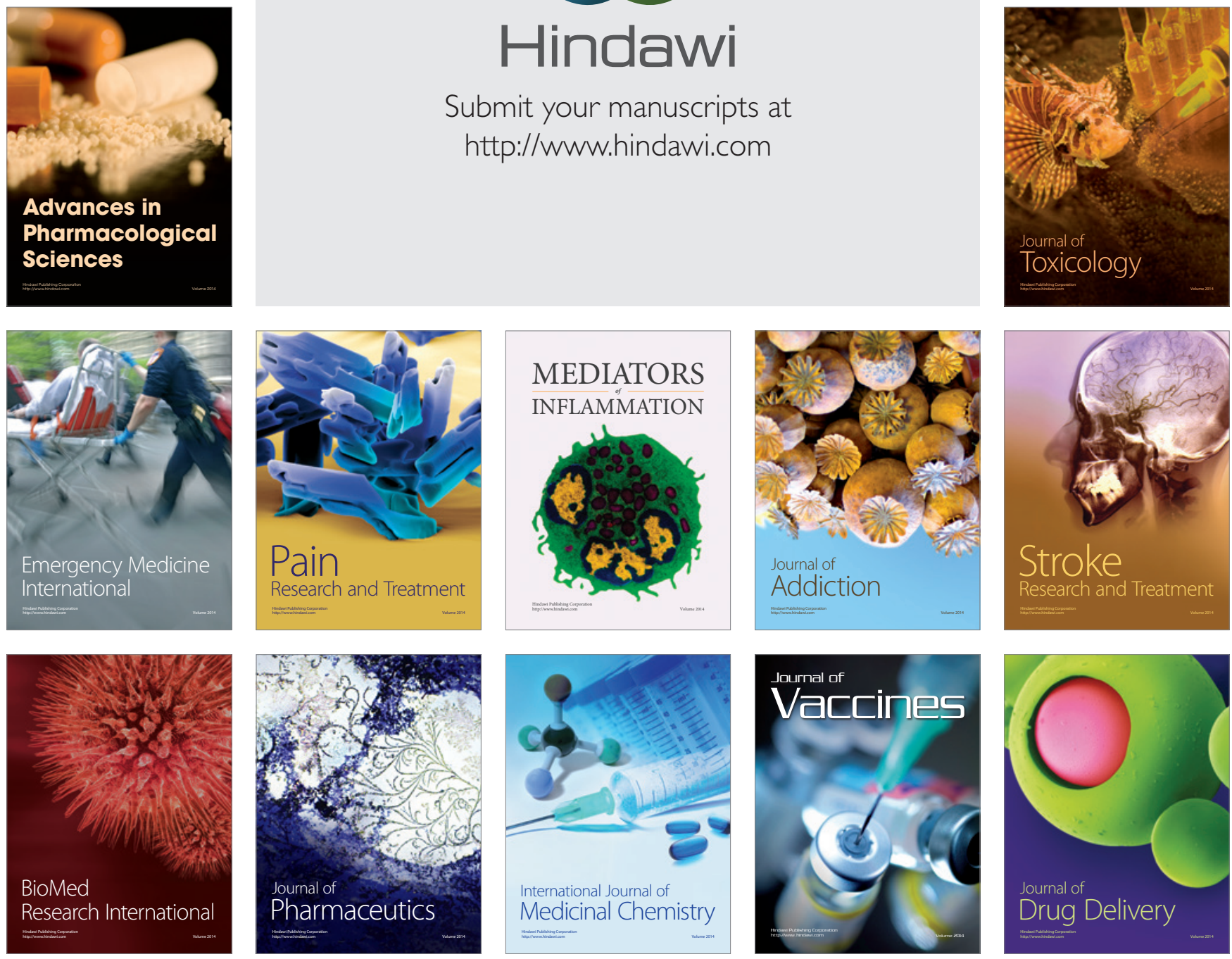